\title{
Factors affecting health-promoting lifestyle profile in Iranian male seafarers working on tankers
}

\section{Fereshteh Baygi ${ }^{1}$, Olaf Chresten Jensen ${ }^{2}$, Fatemeh Mohammadi-Nasrabadi ${ }^{3}$, Mostafa Qorbani ${ }^{4,5}$, Morteza Mansourian ${ }^{6}$, Roksana Mirkazemi ${ }^{7}$, Aliasghar Farshad ${ }^{1}$, Seyed Ali Salehi ${ }^{8}$, Arezoo Haghighian Roudsari ${ }^{9}$, Farzad Shidfar ${ }^{1,10}$}

\author{
${ }^{1}$ Occupational Health Research Centre, Iran University of Medical Sciences, Tehran, Iran \\ ${ }^{2}$ Centre of Maritime Health and Society, Institute of Public Health, University of Southern Denmark, Esbjerg, Denmark \\ ${ }^{3}$ Department of Food and Nutrition Policy and Planning Research, National Nutrition and Food Technology Research Institute, \\ Faculty of Nutrition Sciences and Food Technology, Shahid Beheshti University of Medical Sciences, Tehran, Iran \\ ${ }^{4}$ Non-Communicable Diseases Research Centre, Alborz University of Medical Sciences, Karaj, Iran \\ ${ }^{5}$ Chronic Research Centre, Endocrinology and Metabolism Population Sciences Institute, \\ Tehran University of Medical Sciences, Tehran, Iran \\ ${ }^{6}$ Health Management and Economics Research Centre, Iran University of Medical Sciences, Tehran, Iran \\ ${ }^{7}$ Hooman Research Collaborators Institute, Tehran, Iran \\ ${ }^{8}$ National Iranian Tanker Company, Tehran, Iran \\ ${ }^{9}$ National Nutrition and Food Technology Research Institute, Faculty of Nutrition Sciences and Food Technology, \\ Shahid Beheshti University of Medical Sciences, Tehran, Iran \\ ${ }^{10}$ Department of Nutrition, School of Public Health, Iran University of Medical Sciences, Tehran, Iran
}

\begin{abstract}
Background: Seafaring is a risky occupation that is associated with a high incidence of lifestyle-related diseases. The present study was carried out to examine health promotion behaviour and its associated factors in seafarers of the National Iranian Tanker Company.

Materials and methods: A cross-sectional study was performed on 200 Iranian male seafarers in 2015. A self-administered socio-demographic and Health Promotion Lifestyle Profile II (HPLP-II) questionnaire was completed. One-way analysis of variance was used to identify significant differences among the various departments. The t-test was utilised to compare the HPLP-II scores according to the demographic variables. Multiple linear regression analysis was performed to assess the association between demographic variables and the overall HPLP-II score, in addition to the six health-promoting lifestyle subscale scores. Results: The mean age of the participants was $35.93 \pm 9.51$ years. Most of the seafarers were categorised as having a moderate (32\%) or good lifestyle (61.5\%). The mean lifestyle score was $136.14 \pm 19.90$, with the subscale spiritual growth showing the highest score $(26.16 \pm 5.03)$ and the subscale exercise behaviour showing the lowest score $(19.95 \pm 4.23)$. The lowest score for nutrition was found among the seafarers working in the engine department (engine: $20.41 \pm 4.50$, deck: $23.52 \pm 4.97$, and galley: $24.83 \pm 4.64$ ) $(p<0.05)$. Working in the engine department was found to have a significant negative effect on the nutrition score $(B=-3.57, p<0.05)$. Moreover, educational level was found to have a significant positive effect on spiritual growth $(B=2.97, p<0.05)$.

Conclusions: The findings suggest that health-related issues in this occupation, especially workers in the engine room, are a matter of concern.
\end{abstract}

(Int Marit Health 2017; 68, 1: 1-6)

Key words: health promotion, lifestyle, seafarer, health behaviour 


\section{INTRODUCTION}

Seafaring is a risky occupation that is associated with a high incidence of lifestyle-related diseases such as cardiovascular disease and lung cancer [1]. Recent studies have reported that certain risk factors, such as diabetes, obesity, high blood pressure, and high triglyceride levels, and risky behaviours, such as smoking and low physical activity levels, are highly prevalent in seafarers [2-4]. Moreover, a recent study in European countries revealed that seafaring is associated with the highest incidence rates of all cancers, which might be due to various factors, such as exposure to chemicals and sunlight, as well as lifestyle behaviours such as smoking, alcohol consumption and diet [5]. The high level of risk indicates that this occupational group requires attention with regard to safety and health issues [6]. Despite the high prevalence of certain non-communicable diseases, most of them can be prevented by following some simple steps [7]. Lifestyle is one of the main factors that affect health; therefore, health-promoting lifestyle is an important determinant of health status [8]. Hjarnø et al. [9] conducted a needs assessment study on health promotion interventions for Danish seafarers to identify lifestyle-related risk factors and risk behaviours among employed Danish seafarers in 2007-2008. They studied the seafarers' health, wellbeing, diet, smoking and physical activity, and their findings are clearly in line with the assumption that seafaring is a risky occupation. Moreover, their findings confirm the need for behavioural health-promoting interventions such as healthy cooking courses and physical exercise programmes, which will enable seafarers to have a healthier lifestyle and work environment [9].

Health-promoting lifestyle is composed of various factors, such as wellness, personal fulfilment and self-actualisation, which are used to describe an individual's health-promoting lifestyle profile [7]. Workplace health programmes can be established with the combined efforts of employers, employees and society and can improve the health and well-being of people at work. Workplace health promotion goes beyond what is currently required by health and safety legislation and refers to a coordinated and comprehensive set of strategies that include programmes, policies, benefits, environmental support, and links to the surrounding community that are designed to meet the health and safety needs of all employees $[10,11]$.

Seafaring is a crucial job in Iran, but it is not considered as a priority for health promotion efforts. The environment on board (noise level etc.) ships and the seafarers' work tasks constitute the working conditions, which promote or reinforce unhealthy behaviour. However, seafarers have a second home on board ships during their mission which can last for several months. So, working far from home and difficult working conditions can be a major threat to their health and living conditions. The increasing need for effective and fast transport of goods requires a continuous change in technology and work organisation on board, with new exposures related to health and safety. Therefore, seafarers are also frequently exposed to poor diet and living conditions as well as particular occupational risks [12]. As the seafarers spend months and sometimes years on board, they can be targeted within their social network of co-workers for health promotion programmes. The first step in a workplace health promotion programme is assessment of workplace health and its related factors. Since no study so far has proposed such a programme for Iranian seafarers, the aim of this study was to assess health promotion behaviour in this group based on the Health Promotion Lifestyle Profile II (HPLP-II) instrument and its six subscales: health responsibility, spiritual growth, physical activity, interpersonal relations, nutrition and stress management. Some demographic and other influencing factors are also considered. The results can provide relevant and valid information for the maritime industry and the state authorities and aid in the development of education programmes that can help seafarers become aware of how to adopt a healthy lifestyle.

The present study used a cross-sectional approach, which may limit the findings of the cause-effect relationship. Although all ships meet the international rules with regard to work routine and health issues, because of some cultural aspects, the generalisability of this study may be restricted to Middle-Eastern countries. This is the first study to assess the relationship between the demographic variables of Iranian seafarers and the overall score of the HPLP-II. The findings of the current study have highlighted some problems in tankers and may provide health care workers with ideas for enhancing the quality of seafarers' life on board.

\section{MATERIALS AND METHODS}

Between May and July 2015, a cross-sectional study that was approved by the Iran University of Medical Sciences (IUMS) (approval code 25800) was performed on 7 NITC ships and 231 Iranian male seafarers. Nearly 33 seafarers per ship were assessed using cluster random sampling. All ships under the management of NITC have similar conditions, so this sample can be considered as representative of all Iranian seafarers working on tankers. Iranian nationality seafarers with at least 6 months of experience in sea service were included. Informed consent was obtained from all individual participants included in the study. Participants were asked to complete a socio-demographic self-administered questionnaire. The seafarers were divided into three groups according to their recorded job title: (1) The deck department included the captain, all officers and non-officers on the deck side; (2) the engine 
Table 1. Mean, standard deviation (SD), minimum and maximum score of the lifestyle and its dimension in seafarers working on tankers

\begin{tabular}{lllll}
\hline Dimension & Number of items & Minimum & Maximum & Mean \pm SD \\
\hline Nutrition & 9 & 9 & 36 & $22.57 \pm 4.35$ \\
Spiritual growth & 9 & 9 & 36 & $26.16 \pm 5.03$ \\
Health responsibility & 9 & 9 & 35 & $22.72 \pm 4.42$ \\
Interpersonal relationship & 9 & 9 & 34 & $23.87 \pm 4.16$ \\
Exercise behaviour & 8 & 8 & 32 & $19.95 \pm 4.23$ \\
Stress management & 8 & 8 & 32 & $20.86 \pm 3.92$ \\
Total lifestyle & 52 & 52 & 193 & $136.14 \pm 19.90$
\end{tabular}

department included all officers and non-officers on the engine side; and (3) the galley department included all types of catering crew. The Persian translated version of the HPLP-Il questionnaire was used to investigate the seafarers' lifestyle. A study by Aghamolaei et al. [13] has shown that the translated version of HPLP-II has the desired level of reliability and validity. The self-administered questionnaires were completed by each volunteer within $30 \mathrm{~min}$. All the data were kept strictly confidential.

HPLP-II questionnaire is a instrument developed by Walker et al. [14] to investigate patterns and determinants of health-promoting life style, as well as the effects of interventions to alter life-style. This instrument is a 52-item questionnaire that covers 52 health-promoting behaviours, which can be categorised into six subscales: (1) health responsibility (HR), (2) spiritual growth (SG), (3) physical activity (PA), (4) interpersonal relations (IR), (5) nutrition (N) and (6) stress management (SM) (Appendix 1 - see journal website, supplementary file). Each question is scored on a four-point Likert scale, with 1 representing 'Never' and 4 representing 'Routinely' [13]. Therefore, the total score can range between 52 and 208. The overall HPLP-II score is calculated based on the mean score of the responses to all 52 items. Moreover, the health-promoting lifestyle scores are divided into four levels as follows: 52-90, poor; 91-129, moderate; 130-168, good; and 169-208, excellent. Higher scores in each dimension indicated greater frequency of health-promoting behaviour.

\section{STATISTICAL ANALYSIS}

The data were analysed by the Statistical Package for the Social Sciences software, version 16 (SPSS Inc., Chicago, IL, USA). One-way analysis of variance was used to identify significant differences in the total HPLP-II score and the subscale scores between the three groups, with Tukey's post-hoc test. The $t$-test was utilised to compare the HPLP-II scores according to demographic variables. Pearson correlation was used to examine the association between the HPLP-II scores and the demographic variables. Multiple linear regression (MLR) analysis was performed to assess

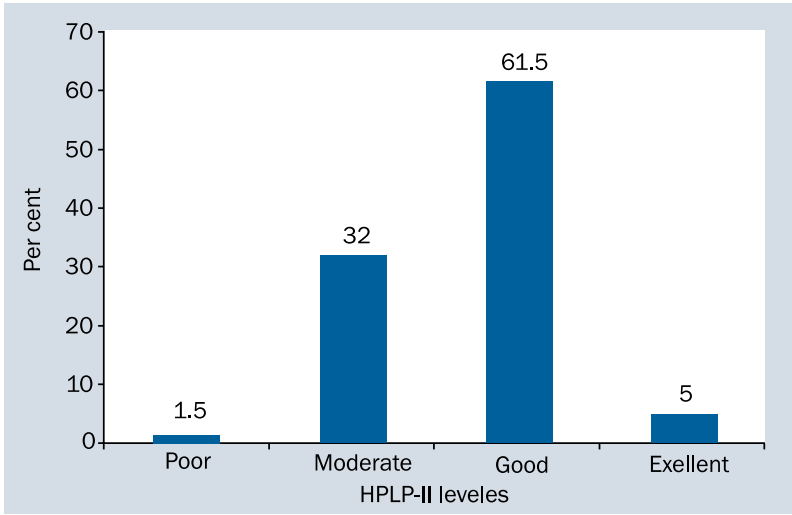

Figure 1. Frequency of each Health Promotion Lifestyle Profile-II (HPLP-II) levels in seafarers

the association of the demographic variables with the overall HPLP-II score and the six health-promoting lifestyle subscale scores. The results of MLR are presented as the beta-coefficient (B) and standard error (SE). The significance level was set at $p<0.05$.

\section{RESULTS}

The mean age of the participants was $35.93 \pm 9.51$ years. The deck, engine and galley departments formed $52.7 \%, 34.1 \%$ and $13.2 \%$ of the total participants respectively. Further, $74 \%$ were married and $22.5 \%$ were single. With regard to education, $35.8 \%$ had a diploma and $64.2 \%$ had an academic degree (data not shown). The response rate for the questionnaire was $86.9 \%$. However, with regard to the influencing variables, the non-respondents were not significantly different from the 200 studied seafarers.

Table 1 depicts the mean, standard deviation, maximum and minimum scores for overall lifestyle profile and its subscales. The mean lifestyle score was $136.14 \pm 19.90$. The subscale spiritual growth had the highest score (26.16 \pm 5.03$)$, while exercise behaviour had the lowest score $(19.95 \pm 4.23)$.

Based on the scores, $32 \%$ of the seafarers were classified as moderate and $61.5 \%$ were classified as good (Fig. 1). 
Table 2. The correlation matrix of the related variables associated with adolescent lifestyle in seafarers working on tankers

\begin{tabular}{|c|c|c|c|c|c|c|c|}
\hline & 1 & 2 & 3 & 4 & 5 & 6 & 7 \\
\hline Nutrition & 1 & & & & & & \\
\hline Spiritual growth & $0.350 *$ & 1 & & & & & \\
\hline Health responsibility & $0.561^{*}$ & $0.324 *$ & 1 & & & & \\
\hline Interpersonal relationship & $0.449 *$ & $0.671^{*}$ & $0.506^{*}$ & 1 & & & \\
\hline Exercise behaviour & $0.537 *$ & $0.281^{*}$ & $0.661^{*}$ & $0.425 *$ & 1 & & \\
\hline Stress management & $0.410 *$ & $0.569 *$ & $0.560 *$ & $0.576^{\star}$ & $0.632^{\star}$ & 1 & \\
\hline Total lifestyle & $0.721 *$ & $0.714^{\star}$ & $0.784 *$ & $0.794 *$ & $0.762 *$ & $0.810 *$ & 1 \\
\hline
\end{tabular}

Table 3. Mean \pm standard deviation of Health Promotion Lifestyle Profile II (HPLP-II) total and sub scale score according to demographic variables in seafarers

\begin{tabular}{|c|c|c|c|c|c|c|c|}
\hline $\begin{array}{l}\text { Descriptive } \\
\text { features }\end{array}$ & Nutrition & $\begin{array}{l}\text { Spiritual } \\
\text { growth }\end{array}$ & $\begin{array}{l}\text { Health } \\
\text { responsibility }\end{array}$ & $\begin{array}{l}\text { Interpersonal } \\
\text { relationship }\end{array}$ & $\begin{array}{l}\text { Exercise } \\
\text { behaviour }\end{array}$ & $\begin{array}{l}\text { Stress } \\
\text { management }\end{array}$ & Total lifestyle \\
\hline \multicolumn{8}{|l|}{ Department } \\
\hline Deck & $23.52 \pm 4.97$ & $27.45 \pm 5.61$ & $22.62 \pm 4.47$ & $24.87 \pm 4.59$ & $20.35 \pm 4.54$ & $21.06 \pm 4.15$ & $139.89 \pm 21.77$ \\
\hline Engine & $20.41 \pm 4.50$ * & $26.93 \pm 6.43$ & $21.61 \pm 5.94$ & $23.25 \pm 5.54$ & $18.58 \pm 4.97$ & $20.19 \pm 5.08$ & $131.0 \pm 27.73$ \\
\hline Galley & $24.83 \pm 4.64$ & $27.41 \pm 5.01$ & $24.08 \pm 3.80$ & $24.58 \pm 3.02$ & $21.33 \pm 2.87$ & $22.50 \pm 3.37$ & $144.75 \pm 18.0$ \\
\hline$P$ & 0.05 & NS & NS & NS & NS & NS & NS \\
\hline \multicolumn{8}{|c|}{ Marital status } \\
\hline Married & $22.50 \pm 4.64$ & $26.21 \pm 5.28$ & $22.50 \pm 4.49$ & $23.92 \pm 4.25$ & $19.49 \pm 4.26$ & $20.57 \pm 4.06$ & $135.22 \pm 21.12$ \\
\hline Single & $22.31 \pm 3.95$ & $27.08 \pm 4.57$ & $22.57 \pm 4.31$ & $24.33 \pm 4.06$ & $20.57 \pm 3.95$ & $21.20 \pm 3.40$ & $138.08 \pm 16.24$ \\
\hline $\mathrm{P}$ & NS & NS & NS & NS & NS & NS & NS \\
\hline \multicolumn{8}{|c|}{ Educational level } \\
\hline Academic & $22.0 \pm 4.19$ & $26.82 \pm 4.71$ & $22.28 \pm 4.42$ & $23.91 \pm 4.89$ & $19.18 \pm 4.42$ & $20.45 \pm 3.81$ & $134.66 \pm 18.20$ \\
\hline Diploma & $23.09 \pm 5.39$ & $26.20 \pm 5.96$ & $22.84 \pm 4.67$ & $24.26 \pm 4.91$ & $20.56 \pm 4.06$ & $21.69 \pm 4.32$ & $138.67 \pm 24.51$ \\
\hline$P$ & NS & NS & NS & NS & NS & NS & NS \\
\hline
\end{tabular}

A significant correlation was found between all subscales $(p<0.001)$. The most significant association was found between stress management and lifestyle $(p<001$, $r=0.810$ ). Further, spiritual growth showed the most significant correlation with interpersonal relationships $(p<0.001$, $r=0.671$ ) (Table 2).

Table 3 shows the association of the mean HPLP-II score and the sub-scale scores with the different demographic groups. The mean nutrition score was the lowest among seafarers in the engine department (engine department: $20.41 \pm 4.50$, deck department: $23.52 \pm 4.97$, galley department: $24.83 \pm 4.64$; $p<0.05$ ). There was no significant difference in overall HPLP-II score and subscales with other demographic variables.

Multiple linear regression showed that working in the engine department had a significantly negative effect on the nutrition score $(B=-3.57, p<0.05)$. Moreover, the education level had a significantly positive association with spiritual growth $(B=2.97, p<0.05)$. The other demographic variables had no significant effect on the overall HPLP-II and lifestyle subscale scores (Table 4).

\section{DISCUSSION}

The present study showed that most of the participating seafarers had a moderate (32\%) or a good lifestyle (61.5\%). However, the scores for the subscales exercise behaviour and stress management were low. Another interesting finding was that the spiritual growth subscale score showed a significant positive association with educational status.

According to the departments in which they worked, the mean score for the nutrition subscale was significantly lower in seafarers working in the engine departments than in those working in the deck and galley departments. In contrast to the findings of the present study, Hjarnø et al.'s study did not report any significant difference in eating behaviour according to the professional status or work places of Danish seafarers [9]. In a study conducted by Hacıhasanoğlu et al. [15] and Karadağ and Yildirim [16], on 981 Turkish university students, the average score for healthy lifestyle behaviour was lower than the present study. This difference could be due to differences in the socio-cultural background of the study population. However, similar to the findings of the 
Table 4. Association and differences - B (SE) - of Health Promotion Lifestyle Profile II (HPLP-II) total and sub scale score with demographic variables in seafarers

\begin{tabular}{|c|c|c|c|c|c|c|c|}
\hline $\begin{array}{l}\text { Descriptive } \\
\text { features }\end{array}$ & Nutrition & $\begin{array}{l}\text { Spiritual } \\
\text { growth }\end{array}$ & $\begin{array}{l}\text { Health re- } \\
\text { sponsibility }\end{array}$ & $\begin{array}{l}\text { Interpersonal } \\
\text { relationship }\end{array}$ & $\begin{array}{l}\text { Exercise } \\
\text { behaviour }\end{array}$ & $\begin{array}{l}\text { Stress } \\
\text { management }\end{array}$ & $\begin{array}{l}\text { Total } \\
\text { lifestyle }\end{array}$ \\
\hline Age [year] & $-0.001(0.074)$ & $-0.058(0.086)$ & $0.062(0.071)$ & $0.019(0.072)$ & $0.61(0.067)$ & $-0.039(0.065)$ & $0.044(0.354)$ \\
\hline $\begin{array}{l}\text { Department: } \\
\text { Engine/Deck } \\
\text { Galley/Deck }\end{array}$ & $\begin{array}{l}-3.57 *(1.31) \\
0.363(1.81)\end{array}$ & $\begin{array}{l}-1.75(1.52) \\
0.361(2.096)\end{array}$ & $\begin{array}{l}-0.453(1.26) \\
0.666(1.74)\end{array}$ & $\begin{array}{l}-2.25(1.28) \\
-0.659(1.76)\end{array}$ & $\begin{array}{l}-1.12(1.18) \\
0.772(1.62)\end{array}$ & $\begin{array}{l}-0.615(1.14) \\
0.96(1.57)\end{array}$ & $\begin{array}{l}-9.77(6.28) \\
2.46(8.64)\end{array}$ \\
\hline $\begin{array}{l}\text { Marital status: } \\
\text { Married/Single }\end{array}$ & $1.074(1.39)$ & $0.526(1.62)$ & $-0.914(1.34)$ & $0.814(1.36)$ & $-2.17(1.25)$ & $-0.389(1.21)$ & $-1.063(6.67)$ \\
\hline $\begin{array}{l}\text { Educational level: } \\
\text { Academic/Diploma }\end{array}$ & $-1.135(1.288)$ & $2.97 *(1.49)$ & $-1.61(1.24)$ & $0.152(1.25)$ & $-1.73(1.15)$ & $-1.42(1.12)$ & $-2.77(6.14)$ \\
\hline
\end{tabular}

present study, most Chinese students in the Larouche [17] study also reported a 'moderate' or 'good' lifestyle. Wei et al. [18] found similar mean scores for the subscales of HPLP-Il with our study among university students in Japan. In contrast, in the United Kingdom, females generally reported more consumption of fruits and vegetables; moreover, male students had a higher level of physical activity, consumed less sweets and had more restful sleep [19]. In a study on a group of students, the highest mean score was reported for interpersonal relationships and stress management and the lowest scores were reported for health responsibility and physical activity [20]. However, our data showed that spiritual growth had the highest score, which was consistent with the Japanese [18] and the Jordanian [21] study. Further, in the present study, the lowest score was allocated to exercise behaviour, despite the fact that most tankers had gym. Thus, it seems that commitment to physical activity programmes may be low in many companies. This is probably because seafarers are given a lot of heavy-duty work, as a result of which they are too tired to exercise after work.

Previous studies have shown a significant positive correlation between the HPLP-Il score and age [21-24]. Bray et al. [25] and others [26, 27] reported a modest association between demographic factors and health-promoting lifestyles; age and education were related to health-promoting lifestyles. In contrast, we found no correlation between the scores and age.

The lack of correlation between health-promoting behaviours and age observed here is probably attributable to the small difference between the ages of the subjects.

In the present study, spiritual growth was positively correlated with educational status. Seafaring has a reputation for being stressful. At ship and during the missions, top level managers who have higher educational level encounter too much work related stress due to tight work schedule and heavy workloads. Since workplace environment in Iran has provided an appropriate atmosphere to develop spiritual growth, top level managers can benefit from this dimension of health-promoting behaviour to beat their stress. In a similar way, an Iranian study showed a significant relationship between the lifestyle scores of adolescents and their parents' educational level. Moreover, another study also reported that spiritual growth and the overall lifestyle score showed the highest correlation [28].

The Department of Defence in the United States of America conducted surveys on health-related behaviours among active duty military personnel and found that the health behaviours of participants improved over the period from 1980 to 2008 , especially with regard to stress management and smoking behaviour [25]. Therefore, ongoing surveys could have a positive effect on the health behaviours of employees.

In 1946, the World Health Organisation defined health in its broader sense as 'a state of complete physical, mental, and social well-being and not merely the absence of disease or infirmity' [29]. Studies show that compared to land-based industries, shipping is a risky industry with a higher incidence of mortality and morbidity among young and middle-aged seafarers [1]. Inequalities in health between seafarers and the population as a whole is not in itself a novelty, but there is definitely a lack of information about what actually causes the divide and the health-promoting methods and subscales that can work in such a situation [1].

Healthy workplace interventions have typically focussed on education, motivational counselling and effortful behaviour change such as individual responsibility for health. Therefore, policy makers in maritime industry should design health promotion educational programmes for hard to access groups on a regular basis. For instance, recently the company has started health promotion programmes on safety and sleep quality of workers which was not interfered with the present study. Also health screening, including measurement of blood pressure, cholesterol, body mass index and blood and urine tests, was conducted annually in our study population. In addition, the employees were covered by insurance and regular visits to the general practitioners.

\section{CONCLUSIONS}

The findings of the present study imply that health-related issues in occupational groups, especially workers in engine rooms, are a matter of concern. There is clearly a need to 
establish health promotion interventions that will focus on the nutrition and physical activity of seafarers. Further, the findings can be used to assess and document potential health and lifestyle risks on tankers, to track health-related trends and to identify high-risk groups and areas that need additional screening or intervention. The results could also be useful for policy makers to help them better understand the nature, causes, effects and consequences of health risks in seafarers working on tankers and to evaluate and guide programmes and policies related to the same. Moreover, these findings can be used for health promotion among hard-to-access groups in public health system research. As part of annual health screening programmes, seafarers should be asked to fill out lifestyle questionnaires and should be made aware of healthy eating habits, exercise, stress, heart disease, diabetes and cancer.

\section{ACKNOWLEDGEMENTS}

This study was funded by Iran University of Medical Sciences (grant No. 25800). The source of the data was the PhD thesis of Ms. Fereshteh Baygi, a student of the Occupational Health Research Centre of Iran University of Medical Sciences. The authors would like to thank the manager and participants of the National Iranian Tanker Company for their important contribution.

\section{ETHICAL CONSIDERATIONS}

This study was proposed to and approved by the Ethics-in-Research Commission of Iran University of Medical Sciences. Also, the informed consent of all participants was obtained before they participated.

\section{FUNDING}

This study was funded by Iran University of Medical Sciences (grant No. 25800).

\section{CONFLICT OF INTEREST}

The authors declare that they have no competing interests.

\section{REFERENCES}

1. Hjarnoe L, Leppin A. Health promotion in the Danish maritime setting: challenges and possibilities for changing lifestyle behavior and health among seafarers. BMC Public Health. 2013; 13: 1165, doi: 10.1186/1471-2458-13-1165, indexed in Pubmed: 24330425.

2. Filikowski J, Rzepiak M, Renke W, et al. Selected risk factors of ischemic heart disease in Polish seafarers. Preliminary report. Int Marit Health. 2003; 54(1-4): 40-46, indexed in Pubmed: 14974776.

3. Hjarnoe L, Leppin A. A risky occupation? (Un)healthy lifestyle behaviors among Danish seafarers. Health Promot Int. 2014; 29(4): 720-729, doi: 10.1093/heapro/dat024, indexed in Pubmed: 23630132.

4. Hansen HL, Hjarnoe L, Jepsen JR. Obesity continues to be a major health risk for Danish seafarers and fishermen. Int Marit Health. 2011; 62(2): 98-103, indexed in Pubmed: 21910112.

5. Oldenburg M, Baur X, Schlaich C. Occupational risks and challenges of seafaring. J Occup Health. 2010; 52(5): 249-256, indexed in Pubmed: 20661002.

6. Jaremin B, Kotulak E. Myocardial infarction (MI) at the work-site among Polish seafarers. The risk and the impact of occupational factors. Int Marit Health. 2003; 54(1-4): 26-39, indexed in Pubmed: 14974775.
7. Shaheen $\mathrm{A}$, Nassar $\mathrm{O}, \mathrm{Amre} \mathrm{H}$, et al. Factors Affecting Health-Promoting Behaviors of University Students in Jordan. Health. 2015; 07(01): 1-8, doi: 10.4236/health.2015.71001.

8. Mozaffarian D, Hao T, Rimm EB, et al. Changes in diet and lifestyle and long-term weight gain in women and men. N Engl J Med. 2011; 364(25): 2392-2404, doi: 10.1056/NEJMoa1014296, indexed in Pubmed: 21696306.

9. Hjarnø L. Health promotion intervention in the maritime setting $[\mathrm{PhD}$ dissertation]. University of Southern Denmark: University of Southern Denmark 2013

10. HSA. Workplace Health Toolkit to Assist Small Businesses. Health and safety Authority, Dublin 2016.

11. CDC. Workplace Health Program Definition and Description. Centers for Disease Control and Prevention; Washington DC, 2016.

12. Jensen OC, Sørensen JFL, Thomas M, et al. Working conditions in international seafaring. Occupational Med. 2006; 56: 393-397.

13. Aghamolaei T, Ghanbarnejad A. Validity and reliability of the Persian healthpromoting lifestyle profile II questionnaire. J Research Health. 2015; 5(3): 358-365.

14. Walker SN, Sechrist KR, Pender NJ. The Health-Promoting Lifestyle Profile: development and psychometric characteristics. Nurs Res. 1987; 36(2): 76-81.

15. Hacıhasanoğlu R, Yıldırım A, Karakurt $P$, et al. Healthy lifestyle behaviour in university students and influential factors in eastern Turkey. Int J Nurs Pract. 2011; 17(1): 43-51, doi: 10.1111/j. 1440-172X.2010.01905.x, indexed in Pubmed: 21251153.

16. Karadağ M, Ylldırım N. Health Behaviors in Health Sciences University Students in Turkey. Social Behavior and Personality: Int J. 2010; 38(1): 43-51, doi: 10.2224/sbp.2010.38.1.43.

17. Larouche R. Determinants of college students' health-promoting lifestyles. Clin Excell Nurse Pract. 1998; 2(1): 35-44, indexed in Pubmed: 12675075

18. Wei CN, Harada K, Ueda K, et al. Assessment of health-promoting lifestyle profile in Japanese university students. Environ Health Prev Med. 2012; 17(3): 222-227, doi: 10.1007/s12199-011-0244-8, indexed in Pubmed: 21987366.

19. El Ansari W, Stock C, John J, et al. Health promoting behaviours and lifestyle characteristics of students at seven universities in the UK. Cent Eur J Public Health. 2011; 19(4): 197-204, indexed in Pubmed: 22432394.

20. Al-Kandari YY. Prevalence of obesity in Kuwait and its relation to sociocultural variables. Obes Rev. 2006; 7(2): 147-154, doi: 10.1111/j. 1467-789X.2006.00231.x, indexed in Pubmed: 16629871.

21. Ammouri A. Demographic Differences in Health Promoting Lifestyle of Adult Jordanians. Jordanian Med J. 2008; 42: 1-9.

22. Al-Kandari F, Vidal VL, Thomas D. Health-promoting lifestyle and body mass index among College of Nursing students in Kuwait: a correlational study. Nurs Health Sci. 2008; 10(1): 43-50, doi: 10.1111/j. 1442-2018.2007.00370.x, indexed in Pubmed: 18257831.

23. Barlas FM, Higgins WB, Pflieger JC, Diecker K. 2011 Health Related Behaviors Survey of Active Duty Military Personnel. USA: Department of Defense, 2011.

24. Bi J, Huang Y, Xiao Ya, et al. Association of lifestyle factors and suboptimal health status: a cross-sectional study of Chinese students. BMJ Open. 2014; 4(6): e005156, doi: 10.1136/bmjopen-2014-005156, indexed in Pubmed: 24951109.

25. Bray RM. et al. DoD Surveys of Health Related Behaviors Among Active Duty Military Personnel. USA: RTI International. 2008.

26. Duffy ME, Rossow R, Herandez M. Correlates of health-promotion activities in employed Mexican American women. Nurs Res. 1996; 45(1): 18-24, indexed in Pubmed: 8570417.

27. Grad FP. The Preamble of the Constitution of the World Health Organization. Bull World Health Organ. 2002; 80(12): 981-984, indexed in Pubmed: 12571728.

28. Golmakani N, Naghibi F, Moharari F, et al. Health Promoting Life style and its Related Factors in Adolescent Girls. Journal of Midwifery and Reproductive Health. 2013; 1(1): 42-49.

29. Lee RLT, Loke AJ. Health-promoting behaviors and psychosocial well -being of university students in Hong Kong. Public Health Nurs. 2005; 22(3): 209-220, doi: 10.1111/j.0737-1209.2005.220304.x, indexed in Pubmed: 15982194. 